\title{
The Oostvaardersplassen Fiasco
}

\author{
Bert Theunissen, Utrecht University
}

\begin{abstract}
The now infamous rewilding experiment in the Dutch Oostvaardersplassen was terminated in 2018 as a consequence of repeated public outcries against the massive crashes of the reserve's herbivore populations during severe winters, particularly the winter of 2017-2018. This essay discusses the background and aims of the experiment and analyzes the causes of its failure. It argues that one of the main causes was the general public's conception of nature as a self-regulating whole that strives for equilibrium, a notion with deep historical roots. The experts involved in the project not only paid insufficient attention to this expectation; they even strengthened it at times, inadvertently or not. If the management regime of the reserve had been better attuned to the public's anxieties about the wildly fluctuating herbivore populations, the 2018 fiasco might have been prevented.
\end{abstract}

$\mathrm{M}$

y case is the now notorious attempt at creating a wilderness reserve in the Oostvaardersplassen (OVP) in the Netherlands. 'The OVP, a small stretch of land of about 22.5 square miles, originated in the late 1960s as a leftover piece from a reclamation project that turned parts of the IJsselmeer, the lake between North Holland and Friesland, into polders. Unsuitable for cultivation, it was left to its own devices and developed into a wetland that was particularly attractive to birds. It became a nature reserve in the mid-1970s, and various measures were taken to create a variety of habitats, wet and dry. In the mid-1990s it was decided that nature should be left to take its course in the area. Regulation of the water level was terminated, and a rewilding experiment that was unique in the Netherlands was begun. ${ }^{2}$

The Dutch biologist Frans Vera was the principal instigator of the project. According to Vera, the widely held view that the Netherlands had been covered by dense forests for most of the postglacial era was incorrect. Instead, a savannah-like landscape had been typical, and the presence of herbivores such as aurochs, wild horses, and red deer had ensured that the open spaces were not overgrown by shrubs and trees. In the OVP this hypothesis might be tested, Vera pro-

Bert Theunissen is Professor of the History of Science at the Institute for History and Philosophy of Science and Director of the Descartes Centre for the History of the Sciences and the Humanities at Utrecht University. His work focuses on the history of the life sciences in the nineteenth and twentieth centuries. Faculty of Science, P.O. Box 80.010, 3508 TA Utrecht, Netherlands; l.t.g.theunissen@uu.nl.

Acknowledgments. I thank my Utrecht colleagues for numerous discussions of this subject.

1 The online sources referenced and quoted in this contribution include the governmental archives in the Dutch National Archives; the websites of the Council on Animal Affairs, the Council for the Judiciary, and the Dutch Forestry Service; the archives of the newspapers De Volkskrant and NRC; and the archives of the weekly De Groene Amsterdammer. Full references are available from the author.

${ }^{2}$ For a discussion in English see George Monbiot, Feral: Searching for Enchantment on the Frontiers of Rewilding (London: Allen Lane, 2013).

Isis, volume 110, number 2. (C) 2019 by The History of Science Society.

All rights reserved. 0021-1753/2019/0110-0019\$10.00. 
posed. The aurochs and wild horses had of course become extinct, but hardy, semiwild lookalikes (reconstructed from domestic breeds) such as Heck cattle and Konik horses might take their place. $^{3}$

The plan was endorsed by the government. Heck cattle and Konik horses were introduced to the OVP in the 1980s, and red deer joined them in the 1990s. These grazers initially performed up to expectation. More and more rare bird and plant species found their way to the OVP, and the reserve was added to the European Union's Natura 2000 network of valuable conservation areas. Overall, the general public's response to these developments was positive, yet the status of the large herbivores was contested by some organizations from the beginning. In 1996 the Council on Animal Affairs, an advisory panel of the Ministry of Agriculture, Nature Conservation, and Fisheries - the body governing the OVP - objected to the ministry's designation of the OVP grazers as wild animals. The OVP was fenced off on all sides by human-made barriers, the council argued, and the grazers could not escape the area in times of food shortage. Therefore, the OVP herbivores were kept animals, and the Dutch Forestry Service, which managed the reserve, should feed them whenever necessary. The Society for the Protection of Animals voiced the same opinion and even took the matter to court-unsuccessfully. The ministry's reaction was one of ambivalence. The herbivores were said to live natural lives, free from human interference, implying that they were wild animals. At the same time, however, the department acknowledged that unnecessary suffering should be prevented by "reactive culling": terminally ill animals were to be shot by the foresters.

Initially, the management regime seemed to work reasonably well. In 2005, however, a cold spell near winter's end resulted in death from starvation of an unprecedented number of grazers, especially Heck cattle, 34 percent of which died. The media published photos and videos of dying animals (which the foresters couldn't euthanize fast enough), and many Dutch citizens were shocked. A public debate erupted among foresters, conservation experts, veterinarians, animal rights activists, and concerned citizens as to whether the experiment should be ended. At the height of the controversy, a newspaper quoted the chairman of the Council on Animal Affairs as saying that the OVP resembled a concentration camp. A debate in Parliament induced the government to ask an international group of experts for advice.

This committee published its report in 2006, concluding that the experiment could be continued if certain conditions were met. The experts established that mortality rates in the OVP, compared to similar areas elsewhere, were not exceptional and that fluctuations in population size were only to be expected. Conditions in the OVP were particularly harsh, however, in that there was neither shelter nor a means of escape for the animals. The committee therefore recommended expanding the reserve by connecting it to other areas in order to provide a greater diversity of habitats. To improve animal welfare, the regime of reactive culling should be extended to include animals that, in late winter, seemed unlikely to survive. ${ }^{4}$

These recommendations were accepted but only partially implemented. Some shelter was provided and various options for expanding the OVP were discussed, but when the economic recession of 2008 set in the government deemed these plans too expensive and canceled them. Thus by 2010 not much had changed, and in that year an unusually cold period that caused mortality rates to peak again resulted in another public outcry and an urgent debate in Parliament.

\footnotetext{
${ }^{3}$ F. W. M. Vera, Grazing Ecology and Forest History (Wallingford, Oxfordshire: CABI, 2000).

${ }^{4}$ ICMO, Reconciling Nature and Human Interests: Report of the International Committee on the Management of the Oostvaardersplassen (ICMO), Wing rapport 018 (The Hague: Wageningen UR, 2006).
} 
A second international committee, reporting on the situation in 2011, underlined the conclusions reached by the first committee. The experts added that neither the relatively small size of the reserve nor the fact that it was fenced off made the situation "unnatural," as many critics had argued. In larger areas, whether they were enclosed or not, grazer populations were known to undergo similar checks, sooner or later. Still, the OVP was special in that its recently reclaimed soil was very fertile, enabling the herbivore populations to increase rapidly under the mild Dutch climate conditions. This implied that the area's carrying capacity in a favorable summer was much higher than in an unusually severe winter. The committee therefore recommended that reactive culling be supplemented by "early-reactive culling," from late autumn onward, of animals that ran a high risk of not making it through the winter. ${ }^{5}$

In the following years the controversy abated somewhat, owing to early-reactive culling and a series of mild winters. Meanwhile, however, a new problem presented itself. Grazer population sizes reached unprecedented levels, and overgrazing progressively denuded the area of shrubs and trees. The projected savannah thus began to look rather like a steppe. Moreover, the wet areas were drying up as a result of leakage to lower areas. As a consequence, the most valuable bird species on the reserve began to disappear. Experts suggested a major "reset" of the area to restore both the dry and wet areas. This proposal was accepted, but shortly before its implementation a calamity occurred.

In early 2018, an extremely wet winter ending with severe frosts put an end to the rewilding experiment. In the eyes of the general public, a carnage took place: more than 60 percent of the grazers had to be shot. Citizen protests were more indignant than ever. Activists attempted to feed the animals, and the authorities called in the riot police to stop them. Even experts who had to that point defended the project fell silent. The Province of Flevoland, then the OVP's governing body, decided to change the management regime drastically. The herbivore populations will henceforth be kept at a constant level by regular culling throughout the year, and the Konik horses are to be removed altogether: they will be relocated. This new plan ignited another public debate. It is clear, however, that the wilderness ideal has lost public support and has been officially relinquished by the authorities.

How can this loss of public support (our explanandum) be explained? According to Han Olff, an ecologist involved in the project, the Dutch public, familiar only with meticulously tended reserves, has come to perceive uncontrolled nature as threatening. Citizens have lost all understanding of "the wild" and do not realize that different norms apply to domestic and wild animals. Such explanations are unconvincing, however. For many critics, the constrained living conditions of the OVP herbivores implied they should be viewed and treated as kept animals, regardless of their original (wild or semiwild) status. This goes to show that, whereas Olff presupposes that norms follow from classifications, it can just as easily be the other way around: classifications can follow from norms. Olffs reading of the public's indignation as caused by fear seems gratuitous. Moreover, the countless public contributions to the OVP debate, rather than testifying to fear of the natural, clearly reveal the general conviction as to the unnatural character of the OVP. Time and again, citizens pointed out that the barriers around the area robbed the animals of the possibility to fend for themselves in adverse times and that, therefore, the OVP did not qualify as wilderness. Many believed that, since there were no predators in the reserve, overpopulation was inevitable, with predictable consequences. As one concerned citizen succinctly put it: "Those cows, horses, and deer have been introduced to the OVP, which

\footnotetext{
${ }^{5}$ ICMO2, Natural Processes, Animal Welfare, Moral Aspects, and Management of the Oostvaardersplassen: Report of the Second International Commission on Management of the Oostvaardersplassen (ICMO2), Wing rapport 039 (The Hague: Wageningen UR, 2010).
} 
is unnatural to begin with; secondly, they can't get out; and thirdly, they have no natural enemy and are not managed properly."

The contested status of both the OVP and the herbivores provides part of the explanation of what went wrong: the herbivores' suffering was deemed unacceptable because they were kept animals living under unnatural, human-made conditions. Yet something more was going on that has so far gone unnoticed. The general public entertained expectations about the OVP as a wilderness reserve that derived from an image of nature with a long history-here comes my historical explanans.

Numerous public reactions in the OVP debate invoked the notion of "the balance of nature," the idea that nature is self-regulating and strives for equilibrium. This is a time-honored trope with ancient roots that influenced ecological thought until well into the twentieth century, as John Kricher, among others, has shown. ${ }^{6}$ Even though it has been discredited by biologists, the assumption that nature strives to maintain equilibrium at the supra-organismic level is still deeply ingrained in popular and sometimes even in professional conceptions of the biological world. ${ }^{7}$ This can be seen in the OVP debate in the repeated remarks about the natural balance (natuurlijk evenwicht) of the grazer populations, which citizens said obviously did not obtain in the OVP. After the winter of 2005 many commentators considered the experiment a failure precisely because of the continuing instability of the populations; for the OVP to qualify as genuine wilderness, balance should have been reached. As a member of Parliament debating the 2005 mortality peak put it: "It is preferable to let nature take its own course without intervention, provided a natural equilibrium sets in. If the equilibrium is threatened to be disturbed, we must intervene." "I define nature as an ecosystem in a balanced state that needs no human intervention," another critic in Parliament said. Similarly, the Council on Animal Affairs held that the OVP experiment would be acceptable only if a stable system developed. The government itself had expressed the same view in its first policy document on the OVP: it expected the herbivore populations to reach stable levels within ten years.

Remarkably, the OVP experts did little to counteract such expectations. Indeed, at times they strengthened them. On the one hand, Vera cited evidence from other reserves showing that fluctuations in population size are in fact quite normal and that it is food availability rather than the presence of predators such as wolves that sets limits to population growth. On the other hand, he and other experts did suggest, inadvertently or not, that self-regulating mechanisms were at work at the supra-organismic level. In red deer, they explained, overpopulation is prevented by the does' capacity to regulate their ovulation: if they have been unable to fatten up sufficiently during the summer, they will not get pregnant. ${ }^{8}$ In this way, a forester wrote, "equilibrium is brought about by nature itself." Yet this argument, repeated time and again in the debates, is utterly misleading. Does have not developed this mechanism for the benefit of the population but to increase their individual chances of successful reproduction. They can't predict the future, and when circumstances are favorable they will reproduce on a massive scale. That is what they did in the OVP in the mid-2010s - until the winter of 2018 ruthlessly broke the trend. (See Figure 1.)

Finally, the experts never seriously considered the risk that a huge population crash might occur-even though it must have been obvious to them that such an event would annihilate

\footnotetext{
${ }^{6}$ John Kricher, The Balance of Nature, Ecology's Enduring Mvth (Princeton, N.J.: Princeton Univ. Press, 2009). See also Daniel B. Botkin, Discordant Harmonies: A New Ecology for the Twenty-first Century (New York: Oxford Univ. Press, 1990); and Botkin, The Moon in the Nautilus Shell: Discordant Harmonies Reconsidered (Oxford: Oxford Univ. Press, 2012).

7 See, e.g., Stephen Budiansky, "Chaos in Eden," New Scientist, 14 Oct. 1995, pp. 33-35.

${ }^{8}$ Frans Vera, Is natuur een constructie? (Amsterdam: Elsevier, 2010), p. 52.
} 


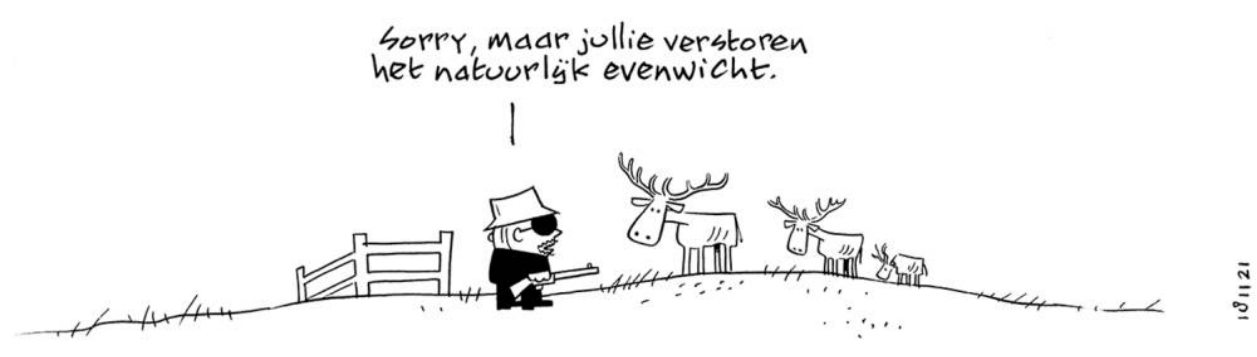

Figure 1. "Sorry, you are disturbing the natural balance." Peter de Wit, cartoonist of the national newspaper De Volkskrant, 21 Nov. 2018 (@ Peter de Wit). De Wit’s comic "Sigmund" features a psychiatrist of that name who is a longtime commentator on the mental state of the nation. This cartoon alludes to the decision that the OVP's red deer are to be regularly culled.

all public support. The second evaluation report had urged the Forestry Service to prepare a scenario for addressing such a contingency, yet this advice was ignored. Was this due to wishful thinking? Did the experts somehow believe that "nature" would not let things get that far?

Historians are not wont to give monocausal explanations, and there were many factors involved in the failure of the OVP experiment. From a biological perspective, for instance, the discrepancy between the area's summer and winter carrying capacities might be identified as a cause. I do think, however, that the historical cause - the notion of the balance of nature-has considerable weight. If the OVP experts had been more sensitive to the public's expectations, they might have attuned their management of the reserve accordingly, especially after the outcries of 2005 and 2010. The 2018 fiasco could then have been prevented. 